IF. Sér. Reg. n. 54 p. 59-77 maio 2016

http://dx.doi.org/10.4322/ifsr.2016.005

ISSN on-line 2179-2372

\title{
PARTICIPAÇÃO SOCIAL E CONTEXTO TERRITORIAL NA IMPLANTAÇÃO DO MOSAICO DE UNIDADES DE CONSERVAÇÃO DO JACUPIRANGA ${ }^{1}$
}

\section{SOCIAL PARTICIPATION AND TERRITORIAL CONTEXT IN IMPLEMENTATION OF JACUPIRANGA CONSERVATION AREAS MOSAIC}

\author{
Ocimar José Baptista BIM ${ }^{2,4}$; Marcos Bührer CAMPOLIM²
}

\begin{abstract}
RESUMO - O presente estudo, realizado entre 2008 e 2013 na região do Vale do Ribeira, Estado de São Paulo, analisou o nível de participação dos ocupantes no processo de criação e gestão do Mosaico de Unidades de Conservação do Jacupiranga e o contexto territorial originado pelas Unidades de Conservação - UCs de proteção integral e de uso sustentável criadas. Utilizou-se como método a análise documental e da cobertura florestal nas UCs e a pesquisa participante, com a realização de 167 entrevistas em campo, utilizando questionários semi-estruturados, com perguntas abertas. Conclui-se que a criação do Mosaico do Jacupiranga proporcionou categorias de UCs apropriadas à cobertura florestal existente e a ocupação humana e a sua implantação contribui para a redução dos conflitos socioambientais relativos ao uso do território para as comunidades que vivem nas áreas recategorizadas.
\end{abstract}

Palavras-chaves: áreas protegidas; comunidades tradicionais; ordenamento territorial; políticas públicas.

\begin{abstract}
The study was conducted between 2008 and 2013 in Vale do Ribeira region, São Paulo, Brazil, and analyzed the level of participation of occupants in the creation and management of Jacupiranga Conservation Areas Mosaic and the territorial context originated by full protection and sustainable use conservation areas created. It was used as a method the document analysis and the forest cover analysis in conservation areas, and the participatory research with 167 interviews conducted in the field using semi-structured questionnaires with open questions. It is concluded that the creation of Jacupiranga Mosaic provided conservation areas categories suitable to the existing forest cover and that human occupation and its implementation contributes to the reduction of environmental conflicts related to the use of the territory for the communities living in recategorized areas.
\end{abstract}

Keywords: protected areas; traditional communities; territorial ordering; public policies.

\footnotetext{
${ }^{1}$ Artigo científico. Recebido para análise em 13.03.2015. Aceito para publicação em 23.05.2016. Publicado on-line em 15.06.2016. 2Instituto Florestal, Rua do Horto, 931, 023777-000 São Paulo, SP, Brasil.

${ }^{3}$ Autor para correspondência: Ocimar José Baptista Bim - ocimarbim@ig.com.br
} 


\section{INTRODUÇÃO}

A relação entre populações e Unidades de Conservação é cercada por problemas de várias ordens, os quais, em última instância, refletem a oposição entre homem e natureza inerente à concepção de conservação e à noção de desenvolvimento econômico e progresso (Diegues et al., 1995). No antigo Parque Estadual do Jacupiranga - PEJ, essa constatação se reproduzia no tocante aos aspectos de criação de UCs de proteção integral de forma imposta pelo Estado e de não resolução da situação das populações residentes nestas áreas. O PEJ foi criado através do Decreto-Lei Estadual $n^{\circ}$ 145, de 8 de agosto de 1969 (São Paulo, 1969), abrangendo uma área de 150 mil hectares distribuídos por seis municípios: Barra do Turvo, Cananéia, Cajati, Iporanga, Eldorado e Jacupiranga. O PEJ, quando criado, englobou em sua área comunidades tradicionais - quilombolas, caiçaras e caboclos/caipiras - que ali já viviam há várias gerações. Restrições de acesso aos recursos naturais, que a legislação ambiental impõe, não permitiam atividades extrativistas e práticas culturais que essas populações realizavam ao longo de anos. As atividades que mais sofreram impacto com a criação do PEJ e demais legislações ambientais foram a agricultura de produção de alimentos, a caça de subsistência, a pesca, a retirada de madeira para construções, lenha e confecção de canoas e o corte do palmito para fins comerciais (Milanello, 1992).

O fato de o Estado ter mantido o Parque (PEJ) abandonado por mais de 20 anos, desde sua criação, disponibilizando poucos funcionários para o trabalho de manejo, uso público, pesquisa e proteção, possibilitou muitas agressões ao patrimônio natural e social por parte de fazendeiros, tais como a retirada ilegal de madeira para comercialização clandestina e a formação de pastagens através de desmatamentos e queimadas, além das ocupações ocorridas nas décadas de 1970 e 1980 por migrantes oriundos das regiões metropolitanas de Curitiba e São Paulo, nas áreas próximas à rodovia BR-116. Em uma área legalmente proibida para as atividades agrícolas, estas ações propiciaram o surgimento de novos conflitos (Arzolla e Paula, 2002; Paula et al., 2004; Bim e Furlan, 2016). O PEJ chegou a ter mais de 8.000 habitantes em 30 bairros rurais (Fundação Instituto de Terras do Estado de São Paulo - ITESP, 2007).

Diante do contexto de grandes conflitos, a partir de 1994, iniciou-se o processo de mobilização social por parte dos ocupantes do PEJ, visando resolução dos mesmos, o qual culminou em 2008, com a formalização da lei de criação do Mosaico de Unidades de Conservação do Jacupiranga - MOJAC. Dessa maneira, a área original de 150.000 ha do antigo PEJ converteu-se em um Mosaico de Unidades de Conservação com 243.885 ha (Figura 1).

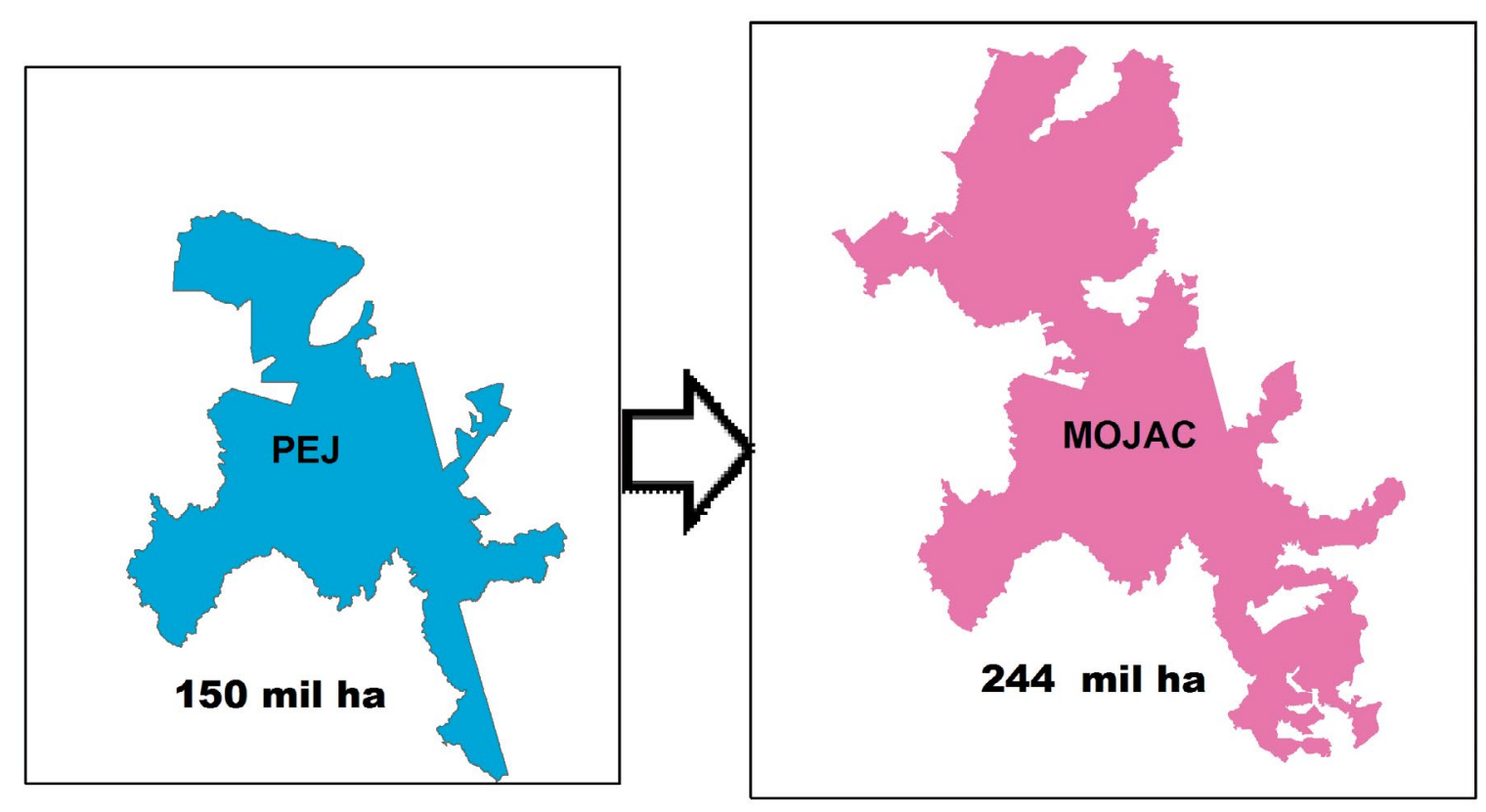

Figura 1. Representação esquemática da alteração dos limites do PEJ para o Mosaico de UCs. Fonte: Autores.

Figure 1. Schematic representation of the change of PEJ limits for Mosaic of Protected Areas. Source: Authors. 
A área de proteção integral foi ampliada para 154.872,17 hectares, sendo subdividida em três Parques: PE Caverna do Diabo - PECD, com 40.219,66 hectares, abrangendo os municípios de Eldorado, Iporanga, Barra do Turvo e Cajati; PE Rio Turvo - PERT, com 73.893,87 hectares, nos municípios de Barra do Turvo, Cajati e Jacupiranga e PE Lagamar de Cananéia - PELC, com 40.758,64 hectares, nos municípios de Cananéia e Jacupiranga. Além dos parques, novas categorias de Unidades de Conservação foram criadas, ficando o MOJAC formado por cinco Reservas de Desenvolvimento Sustentável - RDS com 12.665,06 hectares, duas Reservas Extrativistas - RESEX com 2.790,46 hectares, quatro Áreas de Proteção Ambiental - APA ) com 73.558,09 hectares, totalizando 243.885,15 hectares de áreas protegidas (Lino, 2009).

Apesar da formalização do MOJAC ter possibilitado que mais de 1.400 posseiros deixassem de residir no perímetro do antigo Parque Estadual do Jacupiranga, visto que estas ocupações passaram a integrar UCs de uso sustentável, ainda permanecem no interior das novas Unidades de Conservação de proteção integral aproximadamente 300 famílias, que têm seu modo de vida baseado na agricultura de subsistência e que ainda continuam sob a legislação restritiva (Bim e Furlan, 2016).

Se, por um lado, a criação do antigo Parque Estadual de Jacupiranga seguiu o pressuposto da separação entre sociedade e natureza, seguindo o padrão preservacionista (Brito, 2003) e não levando em conta a presença humana na área, o processo ocorrido no Mosaico do Jacupiranga teve a proposta e sua construção com a participação da sociedade, por meio da qual foram consideradas as características ambientais e sociais do território (Bim e Furlan, 2016).

O presente artigo discute o nível de envolvimento e de participação dos ocupantes no processo de criação e gestão do Mosaico do Jacupiranga e o contexto territorial originado pelas UCs criadas.

Utilizou-se como método a análise documental e da cobertura florestal nas UCs e a pesquisa participante, com realização de entrevistas em campo utilizando questionários semi-estruturados e com perguntas abertas.

\section{MATERIAL E MÉTODOS}

\section{1 Área de Estudo}

A área de estudo encontra-se na região do Vale do Ribeira (Figura 2), Estado de São Paulo. Trata-se de uma das mais antigas regiões de colonização do País. É cortada pelo rio Ribeira de Iguape e forma um polígono irregular com 1,7 milhões de ha, localizado no sudeste do Estado de São Paulo, entre o oceano Atlântico e a Serra do Mar e corresponde a $10 \%$ da área territorial do Estado de São Paulo. O clima é subtropical permanentemente úmido, controlado por massas tropicais e polares marítimas, sendo que as áreas menos elevadas se enquadram no clima do tipo "Cfa", e as restantes no "Cfb"4, que ocorre nas altitudes superiores a $700 \mathrm{~m}$ (Lepsch et al., 1990). A população totaliza pouco mais de 430 mil habitantes, representando menos de 1\% da população total do Estado (Instituto Brasileiro de Geografia e Estatística - IBGE, 2010).

A região, apesar de estar localizada no Estado mais desenvolvido do País e de fazer limite com regiões metropolitanas de São Paulo, Baixada Santista e Curitiba, em função de suas características ambientais, socioeconômicas e de definições geopolíticas. ficou relativamente excluída dos processos de desenvolvimento econômico e da urbanização ocorridos no restante do Estado, e participou com pouca expressão nos principais períodos da economia paulista (Muller, 1980; Ângelo e Sampaio, 1995; Braga, 1998).

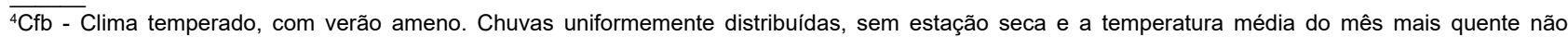
chega a $22{ }^{\circ} \mathrm{C}$. Precipitação de 1.100 a $2.000 \mathrm{~mm}$. Geadas severas e freqüentes, num período médio de ocorrência de 10 a 25 dias anualmente.; $\mathrm{Cfa}$ - Clima subtropical, com verão quente. As temperaturas são superiores a $22^{\circ} \mathrm{C}$ no verão e com mais de $30 \mathrm{~mm}$ de chuva no mês mais seco (Ventura 1964).
} 


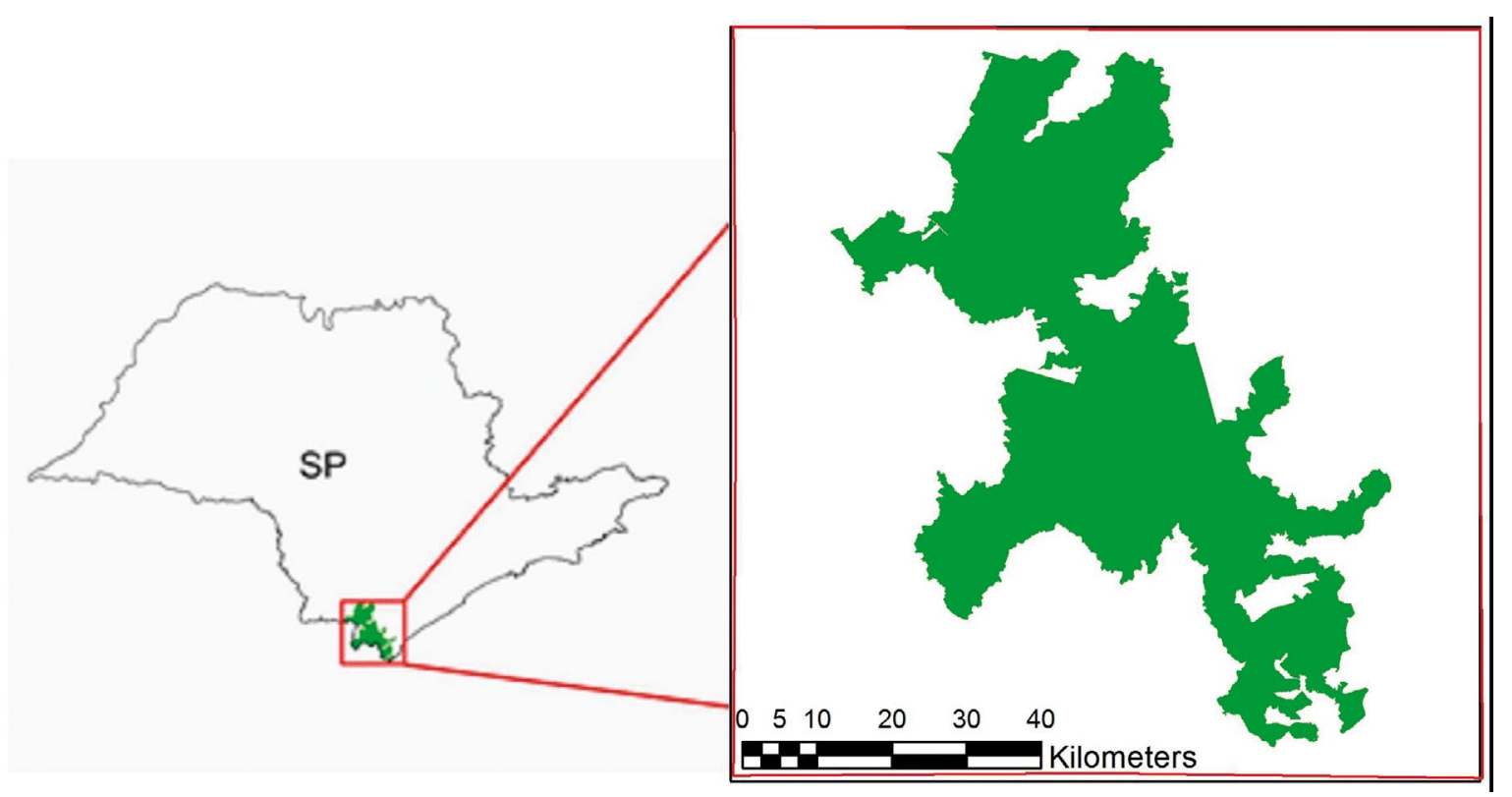

Figura 2. Localização da área de estudo. Fonte: Autores.

Figure 2. Location of the study área. Source: Authors.

O Vale do Ribeira possui o maior índice de cobertura vegetal natural do Estado, em que 1,2 milhão de hectares são de nítida vocação florestal (Lepsch et al., 1990) e é reconhecido como Reserva da Biosfera da Mata Atlântica desde 1993 (United Nations Educational, Scientific and Cultural Organization - UNESCO, 2005) Unesco, 2005) e Sítio do Patrimônio Mundial Natural (Unesco, 1999). Estudos realizados em 1992 indicam que as matas ocupavam $62 \%$ do território do Vale do Ribeira (São Paulo, 1992). Há aptidão para a agricultura e pecuária, mas com muitas restrições de caráter ambiental, topográficas e edafoclimáticas.

No Vale do Ribeira, estão presentes 66 comunidades tradicionais quilombolas, centenas de comunidades caiçaras, ribeirinhas e caboclas e dez grupos indígenas (Instituto Sócio Ambiental - ISA, 2013), cujo modo de vida implica estreita relação com o ambiente natural. A economia dessas comunidades rurais é baseada em um sistema de complementaridade, com atividades ligadas à agricultura, extrativismo, artesanato, turismo e serviços (Instituto para o Desenvolvimento Sustentável e Cidadania do Vale do Ribeira - IDESC, 2009).

Para o estudo, foram analisadas as Unidades de Conservação que compõem o MOJAC e a aplicação de entrevistas ocorreu nas UCs situadas nas áreas de maior conflito, que ficam no entorno da rodovia BR-116, situadas nos municípios de Barra do Turvo e Cajati (Figura 3).

\subsection{Procedimentos Metodológicos}

O estudo foi desenvolvido entre os anos de 2008 e 2013, por meio de pesquisa e análise documental, realização de entrevistas com moradores em campo e análise da cobertura florestal da Unidade de Conservação.

\subsubsection{Pesquisa documental}

A pesquisa bibliográfica, que embasou o estudo, foi fundamentada em uma base teórica que permitiria ampliar a visão dos conflitos socioambientais no Mosaico e em levantamentos de informações sobre as comunidades residentes no MOJAC, seus costumes e sua localização no território. Foram consultados livros, atas dos conselhos das UCs que integram o MOJAC, teses, dissertações e artigos disponíveis na internet.

As informações sobre a porcentagem da cobertura florestal foram apuradas através do mapa de uso da terra do Inventário Florestal do Estado de São Paulo (São Paulo, 2012). Esse mapeamento considerou diferentes fitofisionomias e outros usos, agricultura cíclica e permanente, áreas urbanas e infraestrutura viária. 
BIM, O.J.B.; CAMPOLIM, M.B. Participação social e contexto territorial no Mosaico do Jacupiranga.

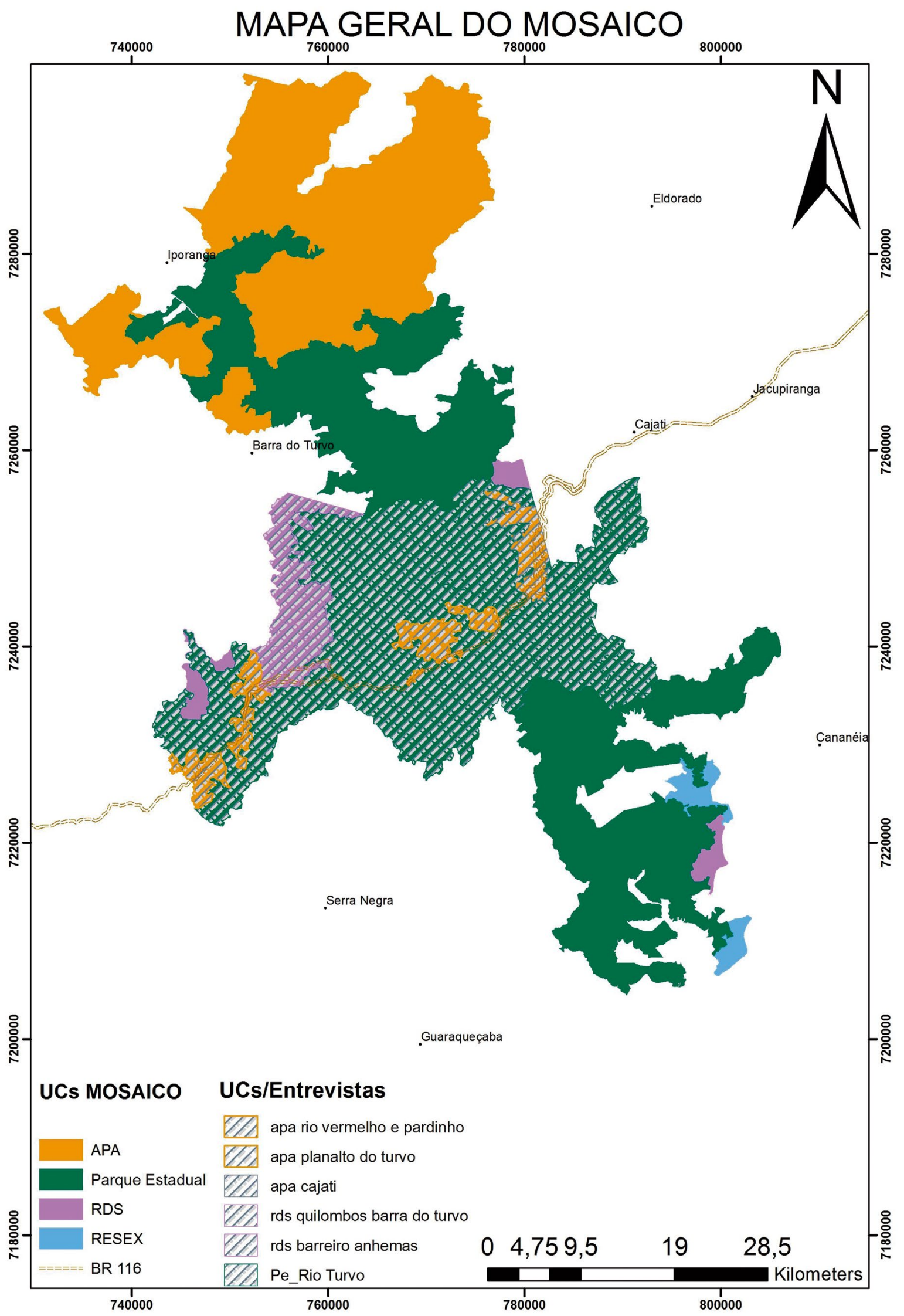

Figura 3 Unidades de Conservação do MOJAC. Fonte: Autores.

Figure 3. MOJAC Conservation Units. Source: Authors. 


\subsubsection{Entrevistas com moradores}

Os procedimentos investigativos basearam-se na pesquisa participante (Brandão, 1984), cujo enfoque de investigação social se busca a plena participação da comunidade na análise de sua própria realidade, com o objetivo de promover a participação social para o benefício dos participantes da investigação. Trata-se de uma atividade educativa de investigação e ação social. A pesquisa participante deve ser pensada como um momento dinâmico de um processo de ação social comunitária (Brandão \& Borges, 2007). Tal procedimento se deu em decorrência da vivência profissional dos autores com o tema e comunidades objeto da pesquisa.

Para a realização de entrevistas, os moradores da região foram selecionados por amostragem não probabilística com critério de intencionalidade (Gil, 2008). Os entrevistados foram os chefes de famílias, identificados por eles próprios, divididos por bairros existentes nas UCs do Mosaico. Foram aplicados questionários semiestruturados, com perguntas abertas (Anexo 1). Foram realizadas 167 entrevistas, correspondente a $12 \%$ das famílias residentes na área de estudo, concentradas nas UCs localizadas nos municípios de Cajati e Barra do Turvo, diante de um universo de população estimada em 1.400 famílias.

O número de entrevistas foi considerado suficiente para a coleta de dados em decorrência da quantidade repetitiva de respostas indicando que foi alcançado o estado de representação para a amostra (Bauer e Gaskell, 2003; Tonissi, 2005).

As entrevistas foram feitas pessoalmente e distribuídas espacial e proporcionalmente, de forma a cobrir toda a área de estudo. A porcentagem de moradores tradicionais e migrantes em cada unidade de conservação foi apurada na análise dessas entrevistas. O questionário semiestruturado continha uma série de perguntas relativas à origem do ocupante, idade, dados socioeconômicos, avaliação do processo de criação e implantação do Mosaico do Jacupiranga e sobre a participação do entrevistado neste processo. Na pesquisa participante, a caracterização da situação da população por meio da coleta de dados socioeconômicos e tecnológicos subsidia a análise (Gil, 2008). A análise dos dados foi dividida em três blocos: caracterização dos ocupantes, opinião sobre a criação do Mosaico e opinião sobre a participação no processo de gestão do Mosaico. As entrevistas foram digitadas em tabelas e analisadas utilizando-se da metodologia de Análise de Conteúdo por meio dos recursos da associação de palavras e temas (Bardin, 1997; Vergara, 2003).

\subsubsection{Análise da cobertura florestal das Unidades de Conservação}

Foi realizado o cálculo da cobertura florestal através do mapa de uso e cobertura do solo do Inventário Florestal do Estado de São Paulo, levando-se em conta a composição da cobertura florestal, utilizando-se do software Arcgis, que possibilitou a apuração das porcentagens de cobertura florestal de cada unidade de conservação.

\section{RESULTADOS E DISCUSSÃO}

Os principais conflitos identificados junto às famílias residentes na área de estudo, concentradas nas UCs localizadas nos municípios de Cajati e Barra do Turvo, têm relação com a questão fundiária e o uso do território, visto que a maioria dos ocupantes recebeu suas terras por herança ou as comprou, e depois descobriu que não podia usá-las. Outros conflitos foram decorrentes da falta de acesso a serviços públicos como estradas, energia elétrica, abastecimento de água, tratamento de esgoto, educação e saúde (Bim e Furlan, 2016).

Se, por um lado, os conflitos podem ser considerados perigosos e destruidores da ordem social, eles também podem constituir-se num processo de construção de novas relações sociais. O conflito pode facilitar a dominação de um grupo social, que se perde em disputas e fica fragilizado. Mas, por outro lado, pode fortalecer os grupos de diferentes, que lutam contra um inimigo comum (Irving, 2006). Os conflitos no antigo PEJ levaram à mobilização local por mudanças que, por sua vez, só ocorreram pela presença do conflito socioambiental dado. 
BIM, O.J.B.; CAMPOLIM, M.B. Participação social e contexto territorial no Mosaico do Jacupiranga.

\subsection{As Unidades de Conservação do MOJAC}

As categorias de Unidade de Conservação que constituem o Mosaico do Jacupiranga estão previstas na Lei 9.985 de 2000, que instituiu o Sistema Nacional de Unidades de Conservação (Brasil, 2000). As caracterizações quanto às famílias existentes no antigo Parque Estadual do Jacupiranga e nas atuais UCs que integram o MOJAC, assim como o uso do solo e os principais conflitos são apresentadas na Tabela 1. As informações são originárias de levantamentos em campo e estudos já realizados (Lino, 2009; São Paulo, 2010; Bim e Furlan, 2016). Destaca-se que todas as UCs do MOJAC possuem Conselhos Consultivos e Deliberativos formalizados e atuantes.

Tabela 1. Caracterização das Unidades de Conservação do Mosaico do Jacupiranga.

Table 1. Characterization of the Conservation Units of Jacupiranga Mosaic

\begin{tabular}{|c|c|c|c|c|c|}
\hline $\begin{array}{l}\text { Unidade de } \\
\text { Conservação }\end{array}$ & $\begin{array}{l}\mathrm{N}^{\circ} \\
\text { famílias } \\
\text { quando } \\
\text { PEJ }\end{array}$ & $\begin{array}{c}\mathrm{N}^{\mathrm{o}} \\
\text { famílias } \\
\text { atual }\end{array}$ & $\begin{array}{l}\text { Caracterização das } \\
\text { comunidades existentes }\end{array}$ & Uso do solo & Conflitos \\
\hline $\begin{array}{l}\text { PE Caverna do Diabo } \\
\text { Área: } 40.219,66 \text { ha } \\
\text { Municípios: Cajati, } \\
\text { Barra do Turvo, } \\
\text { Eldorado e Iporanga }\end{array}$ & 127 & 59 & $\begin{array}{l}\text { - agricultores migrantes: } \\
30 \% \text {; } \\
\text { - moradores tradicionais } \\
\text { com origem Barra do } \\
\text { Turvo e Eldorado: } 70 \% \text {; } \\
\text { - maioria não reside na área. }\end{array}$ & $\begin{array}{l}\text { - 91\% de cobertura } \\
\text { florestal em bom estado } \\
\text { de conservação; } \\
\text { - produção de grãos e } \\
\text { de outros alimentos. }\end{array}$ & $\begin{array}{l}\text { Áreas ocupadas } \\
\text { por } 15 \text { fazendeiros } \\
\text { e pequenos sitiantes } \\
\text { foram incluídas no } \\
\text { novo território do } \\
\text { PECD. }\end{array}$ \\
\hline $\begin{array}{l}\text { PE Rio Turvo } \\
\text { Área: } 73.893,87 \text { ha } \\
\text { Municípios: Barra do } \\
\text { Turvo, Cajati e } \\
\text { Jacupiranga }\end{array}$ & 120 & 120 & $\begin{array}{l}\text { - pequenos agricultores } \\
\text { migrantes: } 60 \% \text {; } \\
\text { - moradores tradicionais: } \\
40 \% \text {; } \\
-50 \% \text { residem na área do } \\
\text { PERT }\end{array}$ & $\begin{array}{l}\text { - } 89,8 \% \text { de floresta } \\
\text { ombrófila densa e } \\
\text { mista em bom estado } \\
\text { de conservação; } \\
\text { - 10,2\% da área com } \\
\text { produção de agricultura } \\
\text { de subsistência (grãos } \\
\text { e outros alimentos), } \\
\text { bananicultura e pecuária } \\
\text { extensiva de corte e } \\
\text { leite. }\end{array}$ & $\begin{array}{l}\text { Regularização } \\
\text { fundiária: muitos } \\
\text { ocupantes desejam } \\
\text { que seus sítios } \\
\text { saiam do Parque e } \\
\text { outros reivindicam } \\
\text { serem indenizados } \\
\text { ou realocados em } \\
\text { áreas próximas ao } \\
\text { Parque. }\end{array}$ \\
\hline $\begin{array}{l}\text { PE Lagamar de } \\
\text { Cananéia } \\
\text { Área: } 40.758,64 \text { ha } \\
\text { Municípios: Cananéia } \\
\text { e Jacupiranga }\end{array}$ & 87 & 26 & $\begin{array}{l}\text { - moradores tradicionais } \\
\text { caiçaras; } \\
\text { - moradores tradicionais } \\
\text { descendentes de alemães } \\
\text { que chegaram à região na } \\
\text { década de } 1930\end{array}$ & $\begin{array}{l}\text { - 95\% da área com } \\
\text { floresta atlântica em } \\
\text { ótimo estado de } \\
\text { conservação. }\end{array}$ & $\begin{array}{l}\text { Questão fundiária } \\
\text { no bairro Santa } \\
\text { Maria e usos de } \\
\text { madeira para } \\
\text { construção de } \\
\text { embarcações. }\end{array}$ \\
\hline $\begin{array}{l}\text { APA de Cajati } \\
\text { Área: } 2.990 \text { ha } \\
\text { Município de Cajati }\end{array}$ & 363 & 363 & $\begin{array}{l}\text { - moradores tradicionais } \\
\text { caipiras-sitiantes: } 54 \% \text {; } \\
\text { - agricultores migrantes } \\
\text { do Sul e do Nordeste, e } \\
\text { fazendeiros de fora da } \\
\text { região: } 46 \% \text {. }\end{array}$ & $\begin{array}{l}\text { - } 41 \% \text { com floresta } \\
\text { ombrófila densa em } \\
\text { seus vários estágios } \\
\text { sucessionais, em bom } \\
\text { estado de conservação; } \\
\text { - } 59 \% \text { com produção de } \\
\text { alimentos, monocultura } \\
\text { da banana e pecuária } \\
\text { de corte e leite. }\end{array}$ & $\begin{array}{l}\text { A questão fundiária } \\
\text { é o maior conflito. } \\
\text { Toda a área está } \\
\text { localizada em terra } \\
\text { pública. }\end{array}$ \\
\hline
\end{tabular}


BIM, O.J.B.; CAMPOLIM, M.B. et al. Participação social e contexto territorial no Mosaico do Jacupiranga.

continuação - Tabela 1

continuation - Table 1

\begin{tabular}{|c|c|c|c|c|}
\hline $\begin{array}{l}\text { Unidade de } \\
\text { Conservação }\end{array}$ & $\begin{array}{c}\mathrm{N}^{\circ} \\
\text { famílias } \\
\text { quando } \\
\text { PEJ }\end{array}$ & $\begin{array}{c}\mathrm{N}^{\mathrm{o}} \\
\text { famílias } \\
\text { atual }\end{array}$ & $\begin{array}{l}\text { Caracterização das } \\
\text { comunidades existentes }\end{array}$ & Uso do solo \\
\hline $\begin{array}{l}\text { APA Planalto do } \\
\text { Turvo } \\
\text { Área: } 2.720 \text { ha } \\
\text { Município: Cajati e } \\
\text { Barra do Turvo }\end{array}$ & 374 & 374 & $\begin{array}{l}\text { - } 81 \% \text { de pequenos } \\
\text { agricultores, migrantes } \\
\text { do Sul, Nordeste e Centro } \\
\text { Oeste } \\
-19 \% \text { de famílias } \\
\text { tradicionais, } \\
\text { caipiras-sitiantes. }\end{array}$ & $\begin{array}{l}\text { - } 61 \% \text { com floresta } \\
\text { ombrófila densa com } \\
\text { transição para ombrófila } \\
\text { mista em vários } \\
\text { estágios sucessionais; } \\
\text { - } 39 \% \text { com pecuária } \\
\text { de corte e leite e } \\
\text { agricultura de } \\
\text { produção de alimentos, } \\
\text { em solos de baixa } \\
\text { fertilidade. }\end{array}$ \\
\hline
\end{tabular}

APA Rio Vermelho/

Rio Pardinho

Área: 3.230 ha

Município: Barra do

Turvo
345

$345 \quad$ - moradores tradicionais:
$32 \%$
- pequenos agricultores
migrantes do Sul e
fazendeiros de outras
regiões: $68 \%$.

$-25,1 \%$ com floresta ombrófila densa em

vários estágios

sucessionais;

$-75 \%$ com agricultura

de produção de alimentos e pecuária de corte e de leite.

Conta com 12 comunidades quilombolas da região de Iporanga e Eldorado.

Área: 64.400,00 ha

Município: Barra do

Turvo, Eldorado e Iporanga

RDS Barreiro/Anhemas

Área: 2.170 ha

Município: Barra do

Turvo
77

77
$-85 \%$ com floresta ombrófila densa; - $25 \%$ com agricultura para a produção de alimentos, produção de banana e pecuária de corte e leite.

- $20 \%$ com floresta
ombrófila densa
em vários estágios
sucessionais;
$-80 \%$ de campo
antrópico para
a agricultura de
produção de alimentos
e da agrofloresta,
criação de pequenos
animais e pecuária.

\author{
A recategorização \\ não agradou a \\ uma parcela de \\ pelo menos \\ 30 pequenos \\ agricultores, que \\ permaneceram nos \\ limites com o PERT e \\ reivindicam a \\ saída da parte de \\ seus sítios de \\ dentro do Parque. \\ A recategorização \\ atendeu quase \\ a totalidade dos \\ agricultores, \\ porém alguns \\ ficaram nos limites \\ do PERT, o que \\ ainda traz \\ conflitos à região.
}

Relacionado com a questão da gestão da área. Os quilombolas consideram que são eles quem deve fazer a gestão do território.

- moradores demandam a ampliação da área da RDS em mais de 2 mil hectares; - pastos instalados em áreas de "cabeceira" e "beira dos córregos"; - uso do fogo e de agrotóxicos. 
BIM, O.J.B.; CAMPOLIM, M.B. Participação social e contexto territorial no Mosaico do Jacupiranga.

continuação - Tabela 1

continuation - Table 1

\begin{tabular}{|c|c|c|c|c|c|}
\hline $\begin{array}{l}\text { Unidade de } \\
\text { Conservação }\end{array}$ & $\begin{array}{l}\mathrm{N}^{\circ} \\
\text { famílias } \\
\text { quando } \\
\text { PEJ }\end{array}$ & $\begin{array}{c}\mathrm{N}^{\mathrm{o}} \\
\text { famílias } \\
\text { atual }\end{array}$ & $\begin{array}{c}\text { Caracterização das } \\
\text { comunidades existentes }\end{array}$ & Uso do solo & Conflitos \\
\hline $\begin{array}{l}\text { RDS dos Pinheirinhos } \\
\text { Área; } 1.510 \text { ha } \\
\text { Município: Barra do } \\
\text { Turvo }\end{array}$ & 60 & 60 & $\begin{array}{l}\text { - moradores tradicionais } \\
\text { caipiras/caboclos: } 80 \% \text {; } \\
\text { - migrantes vindo do Sul, } \\
\text { principalmente do Paraná: } \\
20 \% \text {. }\end{array}$ & $\begin{array}{l}\text { - } 26 \% \text { com floresta } \\
\text { ombrófila densa em } \\
\text { vários estágios } \\
\text { sucessionais; } \\
-74 \% \text { com pecuária } \\
\text { de corte e de } \\
\text { leite, agricultura } \\
\text { de produção de } \\
\text { alimentos e grãos } \\
\text { para comercialização, } \\
\text { sistema agroflorestal; } \\
\text { - ocorrem problemas } \\
\text { com erosão acentuada. }\end{array}$ & $\begin{array}{l}\text { - desprovida de } \\
\text { qualquer tipo de } \\
\text { infraestrutura; } \\
\text { - os moradores } \\
\text { reivindicam a } \\
\text { ampliação da área } \\
\text { da RDS em mais } \\
\text { de } 554 \text { ha. }\end{array}$ \\
\hline $\begin{array}{l}\text { RDS Quilombos } \\
\text { Barra do Turvo } \\
\text { Área; } 5.800 \text { ha } \\
\text { Município: Barra do } \\
\text { Turvo }\end{array}$ & 136 & 136 & $\begin{array}{l}\text { - remanescentes de } \\
\text { quilombos distribuídos } \\
\text { em quatro comunidades } \\
\text { quilombolas: } 84,2 \% \text {; } \\
\text { - agricultores migrantes: } \\
16 \% \text {. }\end{array}$ & $\begin{array}{l}\text { - 60,3\% com floresta } \\
\text { ombrófila densa; } \\
\text { - 39,7\% com } \\
\text { agricultura de produção } \\
\text { de alimentos através } \\
\text { do sistema de pousio } \\
\text { com uso de fogo e da } \\
\text { agrofloresta, criação de } \\
\text { pequenos animais e } \\
\text { pecuária. }\end{array}$ & $\begin{array}{l}\text { Moradores } \\
\text { demandam } \\
\text { a ampliação } \\
\text { dos territórios } \\
\text { quilombolas e } \\
\text { questionam sobre } \\
\text { a sobreposição do } \\
\text { território da RDS } \\
\text { com o território } \\
\text { quilombola. }\end{array}$ \\
\hline $\begin{array}{l}\text { RDS Itapanhapima } \\
\text { Área: } 1.242,70 \text { ha } \\
\text { Município: Cananeia }\end{array}$ & $\begin{array}{c}\text { Não } \\
\text { inserida }\end{array}$ & 17 & $\begin{array}{l}\text { - ocupada por caiçaras } \\
\text { que têm dupla residência } \\
\text { (casa na cidade e na área } \\
\text { da RDS); } \\
\text { - está prevista a } \\
\text { possibilidade de mais } \\
\text { pescadores tradicionais de } \\
\text { Cananéia usufruírem da } \\
\text { RDS para pesca. }\end{array}$ & $\begin{array}{l}\text { - 77,3\% com floresta de } \\
\text { restinga e manguezais; } \\
\text { - extrativismo de } \\
\text { ostras e caranguejo, } \\
\text { pesca e roças } \\
\text { tradicionais para } \\
\text { a produção de } \\
\text { alimentos. }\end{array}$ & $\begin{array}{l}\text { Os moradores } \\
\text { reivindicam a } \\
\text { ampliação da área } \\
\text { em mais de } 512 \\
\text { hectares, pois } \\
\text { afirmam que na RDS } \\
\text { não ficaram áreas } \\
\text { florestadas com a } \\
\text { possibilidade de } \\
\text { uso de madeira. } \\
\text { Definição de novos } \\
\text { beneficiários que não } \\
\text { possuem residências } \\
\text { na RDS. }\end{array}$ \\
\hline
\end{tabular}


continuação - Tabela 1

continuation - Table 1

\begin{tabular}{|c|c|c|c|c|c|}
\hline $\begin{array}{l}\text { Unidade de } \\
\text { Conservação }\end{array}$ & $\begin{array}{l}\mathrm{N}^{\circ} \\
\text { famílias } \\
\text { quando } \\
\text { PEJ } \\
\end{array}$ & $\begin{array}{c}\mathrm{N}^{\circ} \\
\text { famílias } \\
\text { atual }\end{array}$ & $\begin{array}{c}\text { Caracterização das } \\
\text { comunidades existentes }\end{array}$ & Uso do solo & Conflitos \\
\hline $\begin{array}{l}\text { RESEX da } \\
\text { Ilha do Tumba } \\
\text { Área: } 1.228,26 \text { ha } \\
\text { Município: Cananéia }\end{array}$ & $\begin{array}{l}\text { Não } \\
\text { inserida }\end{array}$ & $\begin{array}{l}\text { Não } \\
\text { inserida }\end{array}$ & $\begin{array}{l}\text { Não possui moradores. Foi } \\
\text { criada para garantir o uso } \\
\text { de recursos naturais pelos } \\
\text { caiçaras tradicionais das } \\
\text { comunidades do Ariri e } \\
\text { Maruja. }\end{array}$ & $\begin{array}{l}\text { - 89,4\% com vegetação } \\
\text { de manguezal e restinga; } \\
\text { - extrativismo de madeira } \\
\text { para a construção dos } \\
\text { cercos (arte tradicional } \\
\text { de pesca) e demais } \\
\text { usos tradicionais. }\end{array}$ & $\begin{array}{l}\text { Os moradores } \\
\text { reivindicam a } \\
\text { ampliação da } \\
\text { área da RESEX } \\
\text { em mais de } 598 \\
\text { hectares de modo } \\
\text { a aumentar a área } \\
\text { com floresta para } \\
\text { usos tradicionais. }\end{array}$ \\
\hline $\begin{array}{l}\text { RESEX do Taquari } \\
\text { Área: } 1.662,20 \text { ha } \\
\text { Município: Cananeia }\end{array}$ & $\begin{array}{c}\text { Não } \\
\text { inserida }\end{array}$ & $\begin{array}{l}\text { Não } \\
\text { inserida }\end{array}$ & $\begin{array}{l}\text { Ocorrem poucas } \\
\text { ocupações (ranchos } \\
\text { de pesca). Foi criada } \\
\text { para garantir o uso de } \\
\text { pescadores tradicionais } \\
\text { caiçaras de Cananéia. }\end{array}$ & $\begin{array}{l}\text { A área é composta por } \\
\text { manguezais e leito do } \\
\text { rio Taquari. É realizado } \\
\text { o extrativismo de } \\
\text { caranguejos e ostras e } \\
\text { a pesca artesanal. }\end{array}$ & $\begin{array}{l}\text { Falta de definição } \\
\text { dos beneficiários } \\
\text { da RESEX e } \\
\text { deficiência na } \\
\text { fiscalização. }\end{array}$ \\
\hline
\end{tabular}

PE - Parque Estadual; PEJ - Parque Estadual do Jacupiranga; APA - Área de Proteção Ambiental; RDS - Reserva de Desenvolvimento Sustentável; RESEX - Reserva Extrativista; ha - hectares.

\section{2 Entrevistas com Moradores}

Foram entrevistados 167 moradores dos municípios de Barra do Turvo e Cajati, que estão inseridos nas APAs Rio Vermelho e Rio Pardinho, Cajati e Planalto do Turvo, nas RDS dos Quilombos da Barra do Turvo e Barreiro-Anhemas e no Parque Estadual do Rio Turvo - PERT. Essa região foi escolhida por ser a porção do Mosaico com maior número de ocupantes e que têm influência direta da rodovia BR-116. As entrevistas foram divididas por Unidades de Conservação e seus respectivos bairros. Dessa maneira, foram entrevistados moradores em 21 bairros rurais, conforme a Figura 4.

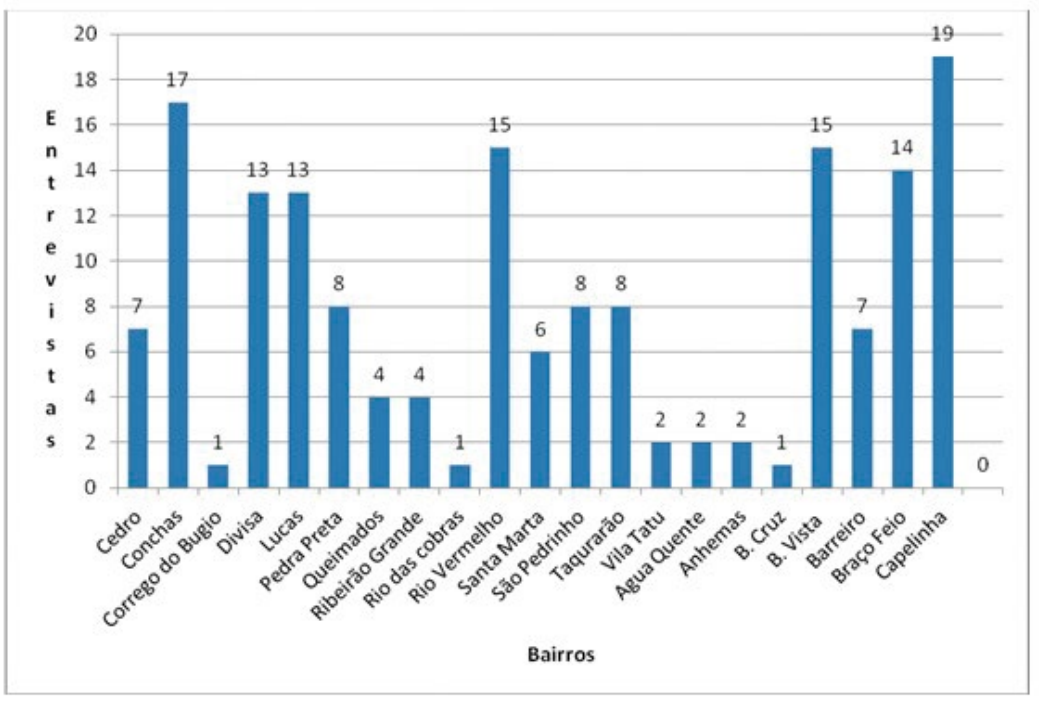

Figura 4. Relação de bairros e número de entrevistas por bairro. Fonte: Autores. 
BIM, O.J.B.; CAMPOLIM, M.B. Participação social e contexto territorial no Mosaico do Jacupiranga.

Figura 4. List of neighborhoods and number of interviews per district. Source: Authors.

\subsection{Caracterização Socioeconômica dos Moradores}

A maioria da população entrevistada (86\%) tem acima de 30 anos de idade. Os serviços públicos são precários na região de estudo. Para 50\% dos entrevistados, a falta de energia elétrica, as péssimas condições das estradas locais, e a deficiência nos setores da saúde e da educação e as precárias condições do saneamento básico foram problemas levantados em praticamente todos os grupos.

Os níveis de escolaridade da região do Mosaico estão, em sua maioria, abaixo da média nacional e estadual e até da média apurada nos municípios da área de abrangência (Quadro 1).

Tabela 1. Comparativo entre o Nível de Escolaridade da Federação, Estado de São Paulo e municípios de Barra do Turvo e Cajati (IBGE, 2010) com o Mosaico do Jacupiranga (entrevistas realizadas).

Table 1. Comparison between the Education Level of the Federation, State of São Paulo and Barra do Turvo and Cajati municipalities (IBGE, 2010) with Jacupiranga Mosaic (interviews).

\begin{tabular}{lccccc}
\hline & \multicolumn{5}{c}{ Nível de instrução \% } \\
\cline { 2 - 6 } & $\begin{array}{c}\text { Sem instrução e } \\
\text { fundamental } \\
\text { incompleto }\end{array}$ & $\begin{array}{c}\text { Fundamental } \\
\text { completo e médio } \\
\text { incompleto }\end{array}$ & $\begin{array}{c}\text { Médio completo } \\
\text { e superior } \\
\text { incompleto }\end{array}$ & $\begin{array}{c}\text { Superior } \\
\text { completo }\end{array}$ & Não determinado \\
\hline Brasil & 50,24 & 17,40 & 23,45 & 8,31 & 0,60 \\
São Paulo & 41,92 & 18,77 & 26,81 & 11,68 & 0,83 \\
Barra do Turvo & 69,86 & 16,88 & 9,36 & 3,86 & 0,04 \\
Cajati & 58,90 & 18,01 & 18,00 & 4,55 & 0,53 \\
Mosaico & 81,00 & 7,00 & 10 & 1 & 1 \\
\hline
\end{tabular}

A caracterização econômica dos ocupantes demonstra que a renda familiar é baixa na região de estudo, quando comparada com a renda do Estado e do País e também quando comparada com a maioria das categorias verificadas nos municípios de Barra do Turvo e Cajati (Quadro 2).

Tabela 2. Comparativo entre o rendimento nominal mensal da Federação, Estado de São Paulo e municípios de Barra do Turvo e Cajati (IBGE, 2010) com o Mosaico do Jacupiranga (entrevistas realizadas).

Table 2. Comparison between the monthly nominal income of the Federation, State of São Paulo and Barra do Turvo and Cajati municipalities (IBGE, 2010) with Jacupiranga Mosaic (interviews).

\begin{tabular}{lcccc}
\hline \multirow{2}{*}{$\begin{array}{c}\text { Mosaico } \\
\text { Município } \\
\text { Unidade da Federação }\end{array}$} & \begin{tabular}{c} 
Classes de rendimento nominal mensal de todos os trabalhos \\
\cline { 2 - 5 }
\end{tabular} & $\begin{array}{c}\text { Mais de 1 a 2 } \\
\text { mínimo }\end{array}$ & $\begin{array}{c}\text { Mais de 3 a 5 } \\
\text { salários mínimos } \\
\text { salários mínimos }\end{array}$ & Sem Renda \\
\hline Brasil & 32,67 & 32,67 & 8,26 & 6,60 \\
São Paulo & 18,01 & 41,34 & 11,43 & 1,90 \\
Barra do Turvo & 37,01 & 28,99 & 6,20 & 16,70 \\
Cajati - SP & 32,75 & 39,40 & 8,85 & 4,11 \\
Mosaico & 55,00 & 32,00 & 8,00 & 5,00 \\
\hline
\end{tabular}

A maioria dos moradores é formada por agricultores, com renda abaixo do mínimo necessário, o que aponta a urgência da implantação de políticas de apoio e fomento à agricultura familiar na região e 
BIM, O.J.B.; CAMPOLIM, M.B. et al. Participação social e contexto territorial no Mosaico do Jacupiranga.

para as UCs de uso sustentável, pois esta situação de pobreza pode ser revertida com a implantação das mesmas.

\subsection{A Participação no Processo de Criação do MOJAC}

Apesar de ter sido desencadeado em um tempo curto, cujas discussões ficaram centralizadas na região da sede do Parque, o processo de criação do Mosaico contou com a participação de $56 \%$ dos entrevistados, os quais receberam informações sobre o que estava acontecendo e/ou participaram do processo. Porém, ficou evidenciado nas entrevistas que não houve um padrão de entendimento e de apropriação das informações pelos moradores durante o processo, já que alguns grupos de moradores, em especial os moradores tradicionais (quilombolas e caipiras), que residem na região há muito tempo e são mais organizados em suas comunidades, demonstraram maior esclarecimento sobre a situação vivenciada do que outros. Os entrevistados apontaram que as informações deveriam chegar às suas residências através de materiais informativos de fácil entendimento ou, ainda, que os moradores deveriam ter sido visitados em suas casas para que pudessem discutir melhor a situação com os técnicos.

\subsection{A Participação na Implantação do MOJAC}

Do total de 167 entrevistados, 76 são considerados moradores tradicionais de Barra do Turvo e Cajati (quilombolas e caboclos/caipiras), representando $45 \%$ do universo pesquisado. Desse universo, $55 \%$ são agricultores migrantes, a maioria vinda de cidades como São Paulo e Curitiba, empurrados pela crise do desemprego da década de 1980 e atraídos pelo baixo valor das terras na região (Bim e Furlan, 2016).

É marcante a relação dos moradores com o lugar. A maioria ( $80 \%$ dos entrevistados) afirma gostar de viver na região e querer que os filhos continuem no lugar junto à família. A tranquilidade, o sossego, a segurança e a natureza são os principais motivos apontados para permanência no lugar. A maioria dos entrevistados (68\%) não sabia que vivia numa área protegida e com restrições legais. Esse desconhecimento é mais comum entre os migrantes que, em sua maioria, chegaram à região sem saber das restrições ambientais impostas pela criação do PEJ. Mesmo os moradores tradicionais não compreendiam muito bem essa situação. Os problemas enfrentados revelam o conflito gerado com a aplicação da legislação ambiental relacionada à proibição do uso do território. Destaca-se também que a solução desses problemas é sentida por $56 \%$ dos entrevistados, a partir das mudanças ocorridas no território com a criação do MOJAC. Os entrevistados sabem das mudanças ocorridas no território, porém ainda há dúvidas sobre o que é o Mosaico, o seu significado. Nessa questão, constata-se que os moradores tradicionais têm apropriado mais conhecimento sobre o tema do que os agricultores migrantes, em decorrência da maior participação no processo de criação do MOJAC e na gestão das UCs criadas. Esses grupos tradicionais possuem uma relação histórica com o lugar e têm suas organizações comunitárias atuantes e fortes, que se apoiam mutuamente e trocam informações sobre os temas que são de seus interesses, num processo de aprendizagem social (Jacob et al., 2013).

A maioria dos entrevistados (64\%) considera que as mudanças ocorridas fizeram diferença tanto na vida como no trabalho com a terra, e 33\% identificaram uma série de atividades ligadas à agricultura e ao uso do território que agora podem desenvolver nas áreas recategorizadas e que antes não podiam. Apesar de não apresentarem clareza na enunciação do significado de Mosaico, 50\% dos entrevistados consideram que o mesmo está funcionando e relacionam este funcionamento principalmente com a chegada da energia elétrica e a melhoria das estradas. Porém, nos locais onde essas políticas públicas ainda não chegaram, a demora é associada ao não funcionamento do Mosaico. Para os entrevistados que ainda permanecem no interior do PE do Rio Turvo, aliada à ausência dos serviços públicos, a questão fundiária não resolvida é o principal motivo para apontarem o não funcionamento do Mosaico.

Os poucos entrevistados que indicaram a piora na situação com a implantação do Mosaico são os moradores que ainda permaneceram no PERT e que agora têm clareza de que estão em uma área de proteção 
BIM, O.J.B.; CAMPOLIM, M.B. Participação social e contexto territorial no Mosaico do Jacupiranga.

integral e o que isto significa em termos de restrições de usos no território.

De modo geral, os entrevistados têm a percepção de que, em relação à conservação, a situação melhorou com o Mosaico.

A maioria dos entrevistados (59\%) participou ou participa dos conselhos das UCs, nos quais buscam informações ou discutem sobre o que está acontecendo, ou ainda debatem sobre as atividades que podem ou não serem executadas em áreas do Mosaico. A maioria dos que não participam justifica que não fica sabendo da realização das reuniões ou porque tem dificuldades para participar, demonstrando que há disposição para esta ação. Mais da metade dos entrevistados considerou-se informada sobre o processo de mudanças ocorridas na região, sendo esta também a porcentagem de pessoas que se sentiram esclarecidas sobre o processo de criação do Mosaico.

\section{CONSIDERAÇÕES FINAIS}

O método utilizado para o levantamento das informações com os moradores do Mosaico realização de entrevistas de forma aleatória - demonstrou ser adequado para a pesquisa, pois apresentou, entre seus resultados, a dimensão da origem e a distribuição da população residente no território estudado.

Os conflitos decorrentes da existência do Parque Estadual do Jacupiranga contribuíram para a mobilização local por mudanças que, por sua vez, só ocorreram pela presença do conflito socioambiental dado.

As entrevistas confirmaram dados que subsidiaram a elaboração da proposta de lei do Mosaico, ou seja, nas áreas do antigo PEJ, que foram recategorizadas como RDS, a maioria dos moradores é formada por comunidades tradicionais, enquanto nas regiões recategorizadas como APAs predominam os agricultores migrantes.

A implantação do Mosaico vem desencadeando um processo de participação das comunidades nos 13 conselhos consultivos e deliberativos das unidades de conservação criadas, o que tem possibilitado a construção de acordos para um ordenamento territorial que viabilize a conservação e o desenvolvimento local.

Conclui-se que a criação do Mosaico do Jacupiranga proporcionou categorias de UCs apropriadas à cobertura florestal existente e à ocupação humana e seus usos e implantação contribuíam para a redução dos conflitos socioambientais relativos ao uso do território pelas comunidades que vivem nas áreas recategorizadas de uso sustentável. Nas áreas de proteção integral, apesar do conflito ainda existente, ocorre o entendimento por parte dos ocupantes quanto às restrições ambientais impostas e estão sendo desenvolvidas realocações acordadas dos mesmos para unidades de conservação de uso sustentável.

\section{REFERÊNCIAS BIBLIOGRÁFICAS}

ÂNGElO, S.; SAMPAIO, P. A. Políticas públicas, agricultura e desmatamento no Vale do Rio Ribeira de Iguape. In: POLÍTICAS públicas, agricultura e desmatamento no Brasil - estudo de caso $n^{\circ} 5$. São Paulo: Instituto de Pesquisas Ambientais, 1995. 79 p.

ARZOLLA, F.A.D.P.; PAULA, G.C.R. Parque Estadual Jacupiranga: desafios à sua implantação (um sinal de alerta). In: CONGRESSO BRASILEIRO DE UNIDADES DE CONSERVAÇ̃̃O, 3., 2002, Fortaleza. Anais... Fortaleza: Rede Nacional Pró-Unidades de Conservação; Fundação O Boticário de Proteção à Natureza; Associação Caatinga, 2002. p. 234-243.

BARDIN, L. Análise de Conteúdo, São Paulo: Edições 70, 1977. 229 p. 
BAUER, M.W.; GASKELL, G. Towards a paradigm for research on social representations. Journal for the Theory of Social Behavior, v. 29, n. 2, p. 163-186, 1999.

BIM, J.B.; FURLAN, S.A. Mosaico do Jacupiranga - Vale do Ribeira/SP: conservação, conflitos e soluções socioambientais. Revista Agrária, n. 18, p. 4-36, 2016.

BRAGA, R. Planejamento regional no estado de São Paulo: a experiência do Vale do Ribeira nas décadas de 1970 a 1980. 1998. 226 f. Tese (Doutorado em Geografia ) - Departamento de Geografia, Faculdade de Filosofia, Letras e Ciências Humanas, Universidade de São Paulo, São Paulo.

BRANDÃO, C.R. Repensando a pesquisa participante. São Paulo: Brasiliense, 1984. 252 p.

.; BORGES, M.C. A pesquisa participante: um momento da educação popular. Rev. Ed. Popular, v. 6, p. 51-62, jan./dez. 2007.

BRASIL. Lei $\mathrm{n}^{\circ}$. 9.985 de 18 de julho de 2000 - Institui o Sistema Nacional de Unidades de Conservação da Natureza - SNUC. Diário Oficial da União, 19 jul. 2000.

BRITO, M.C.W. Unidades de conservação: intenções e resultados. São Paulo: Annablume, 2003. 230 p.

DIEGUES, A.C. et al. Conflitos entre populações humanas e Unidades de Conservação na Região da Mata Atlântica. São Paulo: NUPAUB-USP, 1995. 283 p.

FUNDAÇÃO INSTITUTO DE TERRAS DO ESTADO DE SÃO PAULO - ITESP. Cadastro geral de ocupantes do Parque Estadual do Jacupiranga. São Paulo: ITESP, 2007. (2170 Registros) (Documento Interno - Banco de Dados).

GIL, A.C. Métodos e técnicas de pesquisa social. São Paulo: Atlas, 2008. 216 p.

INSTITUTOL BRASILEIRO DE GEOGRAFIA E ESTATÍSTICA - IBGE. Censo 2010. Disponível em: <http://www.sidra.ibge.gov.br/bda/tabela/protabl.asp>. Acesso em: jul. 2012.

INSTITUTO PARA O DESENVOLVIMENTO SUSTENTÁVEL E CIDADANIA DO VALE DO RIBEIRA IDESC. Levantamento de turismo e economia solidária no Vale do Ribeira. IDESC, 2009. Disponível em $:<$ http://www.idesc.org.br/economia_solidaria.asp1>. Acesso em: 14 dez. 2015.

INSTITUTO SÓCIO AMBIENTAL - ISA. Inventário cultural de quilombos do Vale do Ribeira. São Paulo: ISA, 2013. p. 13-377.

IRVING, M.I. Áreas protegidas e inclusão social: construindo novos significados. Rio de Janeiro: Aquarius, 2006. p. 91-113.

JACOB, P.R. et al. Aprendizagem social e unidades de conservação. São Paulo: IEE/PROCAM, 2013. 94 p.

LEPSCH, I.F. et al. Macrozoneamento das terras da região do rio Ribeira de Iguape, SP. Campinas: Instituto Agronômico, 1990. 181 p. (Boletim Científico, 19).

LINO, C.F. Mosaico de Unidades de Conservação do Jacupiranga. São Paulo: Conselho Nacional da Reserva da Biosfera da Mata Atlântica, 2009. 76 p. (Caderno no 37 da Reserva da Biosfera da Mata Attântica).

MILANELLO, M. Comunidades tradicionais do Parque Estadual da Ilha do Cardoso e a ameaça do turismo emergente. In: CONGRESSO NACIONAL SOBRE ESSÊNCIAS NATIVAS, 2., 1992, São Paulo. Anais... São Paulo: UNIPRESS, 1992. p. 1109-1111. (Rev. Inst. Flor., v. 4, n. único, 1992, pt. 4, Edição especial).

MÜLLER, G. Estado, estrutura agrária e população: estagnação e incorporação regional. Rio de Janeiro: Vozes, 1980. $141 \mathrm{p}$.

PAULA, G.C.R. et al. A ocupação irregular na faixa de influência da rodovia Régis Bittencourt (BR - 116) e a degradação das florestas na porção central do Parque Estadual de Jacupiranga. In: CONGRESSO 
BRASILEIRO DE UNIDADES DE CONSERVAÇÃO, 4., 2004, Curitiba. Anais... Curitiba: Rede Nacional Pró-Unidades de Conservação; Fundação O Boticário de Proteção à Natureza, 2004. p. 298-306.

SÃO PAULO (Estado). Secretaria do Meio Ambiente. Programa Olho Verde. São Paulo, 1992. 115 p.

SÃO PAULO (Estado). Decreto-lei $\mathrm{n}^{\circ} 145$, de 8 de agosto de 1969. Dispõe sobre a criação do Parque Estadual de Jacupiranga e dá outras providências. Assembleia Legislativa. Secretaria Geral Parlamentar. Departamento de Documentação. Disponível em: <http://www.al.sp.gov.br/repositorio/legislacao/decreto. lei/1969/decreto.lei-145-08.08.1969.html>. Acesso em: 6 fev. 2015.

Fundação Florestal. Plano de utilização das reservas de desenvolvimento sustentável e reserva extrativistas do MOJAC. São Paulo: FF, 2010. 267 p. (Documento interno).

. Instituto Florestal. Inventário florestal do Estado de São Paulo. Disponível em: $\overline{<\mathrm{http}: / /}$ www.iflorestal.sp.gov.br/sifesp/inventario.html>. Acesso em: jun. 2012.

TONISSI, T.M.R. Percepção e caracterização ambientais da área verde da microbacia do córrego da Água Quente (São Carlos, SP) como etapas de um processo de educação ambiental. 2005. $281 \mathrm{f}$. Tese (Doutorado em Ciências da Engeharia Ambiental) - Escola de Engenharia de São Carlos, Universidade de São Paulo, São Paulo.

UNITED NATIONS EDUCATIONAL, SCIENTIFIC AND CULTURAL ORGANIZATION - UNESCO. World Heritage Nomination - IUCN Technical Evaluation: Atlantic Forests (Southeast) Brazil. Gland: IUCN, 1999. p. 1-8.

World network of biosphere reserves - SC/EES. Paris: The MAB Program, 2005. 19 p.

VENTURA, A. Problemas técnicos da silvicultura paulista. Silvic. em S. Paulo, v. 3, n. 3, p. 61-80, dez. 1964. SÃO PAULO (Estado).

VERGARA, S.C. Projetos e relatórios de pesquisa em administração. 4. ed. São Paulo: Atlas, 2003. 94 p. 


\section{QUESTIONÁRIO n. Comunidades}

DATA DA ENTREVISTA

ENTREVISTADOR

Pode Gravar ( ) Sim ( ) Não

INFORMAÇÕES GERAIS

ENTREVISTADO

ENDEREÇO:

Unidade de Conservação:

Quanto Tempo mora aqui?

De onde veio - origem

\section{CARACTERIZAÇÃO DOS HABITANTES DA CASA}

\begin{tabular}{|l|l|l|l|l|l|}
\hline Nome & Sexo & Parentesco & Escolaridade & Idade & Ocupação \\
\hline Entrevistado & & & & & \\
\hline & & & & & \\
\hline
\end{tabular}

\section{CONDIÇÕES DA MORADIA}

Condições de ocupação:
( ) própria
( ) cedida
( ) parentes
( ) alvenaria ( ) madeira
( ) pau a pique
( ) outro tipo

Telhado: ( ) telha de barro

( ) alumínio

( ) amianto

( ) palha

( ) outro

Número de cômodos:

Aparelhos eletrônicos:

Energia:
( ) pública
( ) gerador coletivo
( ) gerador próprio
( ) gás ( ) lamparina ( ) não possui

\section{Abastecimento de água:}

( ) pública

( ) poço próprio

( ) poço público

( ) rio

( ) fonte

( ) não possui

Quantas torneiras tem?

Banheiro: Quantidade: ( ) alvenaria
( ) madeira
( ) interno
( ) externo

Esgoto:

( ) rede pública

( ) fossa séptica

( ) fossa seca

( ) outro

Cozinha:
( ) interna
( ) externa 
BIM, O.J.B.; CAMPOLIM, M.B. Participação social e contexto territorial no Mosaico do Jacupiranga.

\section{OPINIÃO SOBRE A CRIAÇÃO DO MOSAICO}

1- Por que o sr. veio morar aqui? De onde veio?

2- O senhor(a) gosta de viver aqui? Sim ( ) Não ( )

Por que?

3- O que mais lhe agrada nesse lugar?

4- O sr. gostaria que seus filhos também vivessem aqui?

Por que?

5- Que tipo de problemas/situações o sr. enfrentou para trabalhar na terra?

6-O senhor(a) consegui resolver alguns desses problemas? Quais?

7- O sr. sabia que aqui era um parque estadual e agora mudou para mosaico?

8- O que senhor(a) entende por Mosaico de Unidade de Conservação? (fale uma/algumas palavras que o(a) senhor(a) acha que é Mosaico)?

9- Na sua vida e de sua família, agora faz diferença ser um Parque ou Mosaico?

Por que?

10- O Sr. acha que tem diferença na sua vida e de sua família entre antes, quando era parque, e agora com o Mosaico?

11- O que mudou na sua vida com a criação do MOSAICO? Fale três coisas que mudaram com o Mosaico.

12 - O que mudou no seu trabalho com a criação do Mosaico?

13- O que não podia fazer quando era parque?

14- O que agora pode ser feito, com a mudança para Mosaico?

15- Você acha que o MOSAICO está funcionando na prática?

16- Na sua opinião o que não está funcionando?

17- O que melhorou?

18- O que piorou?

IF Sér. Reg. n. 54 p. 59-77 maio 2016 
BIM, O.J.B.; CAMPOLIM, M.B. et al. Participação social e contexto territorial no Mosaico do Jacupiranga.

19- Na sua opinião, o que deveria ser feito para melhorar?

20- O que o senhor(a) acha que não é bom para a natureza que o pessoal faz contra a natureza?

\begin{tabular}{|c|c|c|}
\hline $\begin{array}{l}\text { 21- O sr. acha que ainda acontece: } \\
\text { ( ) desmatando } \\
\text { ( ) caçando } \\
\text { ( ) cortando palmito, } \\
\text { ( ) colocando fogo }\end{array}$ & $\begin{array}{l}\text { 22- O sr. acha que o pessoal } \\
\text { continua desmatando? } \\
\text { ( ) sim } \\
\text { ( ) não }\end{array}$ & $\begin{array}{l}\text { 23- O sr. acha que o pessoal } \\
\text { continua caçando? } \\
\text { ( ) sim } \\
\text { ( ) não }\end{array}$ \\
\hline $\begin{array}{l}\text { 24- O sr. acha que o pessoal } \\
\text { continua cortando palmito? } \\
\text { ( ) sim } \\
\text { ( ) não }\end{array}$ & $\begin{array}{l}\text { 25- O sr. acha que o pessoal } \\
\text { continua colocando fogo? } \\
\text { ( ) sim } \\
\text { ( ) não }\end{array}$ & $\begin{array}{l}\text { 26- Comparando com a época que } \\
\text { era Parque, o sr. acha que os } \\
\text { problemas acima como estão } \\
\text { agora: } \\
\text { ( ) diminuiu } \\
\text { ( ) aumentou } \\
\text { ( ) continua do mesmo jeito }\end{array}$ \\
\hline
\end{tabular}

27- O sr. pode falar uma coisa boa que pessoal faz aqui em favor da natureza?.

\section{SUA OPINIÃO SOBRE A PARTICIPAÇÃO DO SENHOR(A) NA CRIAÇÃO DO MOJAC}

28- O senhor(a) participa das reuniões dos conselhos? ( ) Sim （ ) Não Por que?

29- O sr. recebeu informações sobre o processo da criação do Mosaico?

30- Em caso positivo, o sr. se sentiu esclarecido sobre a criação do Mosaico com as informações recebidas?

31- Em caso negativo, que tipo de informação o sr. acha que faltou?

32- O sr. participou das reuniões de criação do Mosaico?

33- O que o sr. achou dessas reuniões?

34- O sr. sabe se outros moradores participaram das reuniões da criação do Mosaico?

35- O sr. sabe o que os outros moradores falam sobre a criação do Mosaico? 
BIM, O.J.B.; CAMPOLIM, M.B. Participação social e contexto territorial no Mosaico do Jacupiranga.

36- Renda da família

Salário fixo: ( ) sim ( ) não

Número de aposentados morando na casa: ( ) nenhum

Tipo de aposentadoria: rural ( ) outra ( )

Recebe algum auxílio federal/estadual/municipal: ( ) sim （ ) não

( ) Bolsa Família ( ) Bolsa Escola ( ) Aposentadoria ( ) Outras 